Check for updates

Cite this: RSC Adv., 2021, 11, 15161

Received 29th January 2021

Accepted 12th April 2021

DOI: $10.1039 / \mathrm{d} 1 \mathrm{ra00772f}$

rsc.li/rsc-advances

\section{Catalyst-free one-pot, four-component approach for the synthesis of di- and tri-substituted $\mathrm{N}$ - sulfonyl formamidines $\uparrow$}

\author{
Ai-Ran Liu, ${ }^{a}$ Lei Zhang, ${ }^{a}$ Jiao $\mathrm{Li}^{\mathrm{a}}$ and Abudureheman Wusiman (D) *ab \\ A straightforward one-pot, multicomponent approach was developed to synthesize di- and tri-substituted \\ $\mathrm{N}$-sulfonyl formamidines from sulfonyl chlorides, $\mathrm{NaN}_{3}$, ethyl propiolate, and primary/secondary amines \\ under mild conditions without catalysts or additives. Structural analysis of the di-substituted sulfonyl \\ formamidines indicated formation of the E-syn/anti isomeric form. Tri-substituted analogues only \\ formed $E$-isomers.
}

Amidines are important nitrogen-containing organic compounds owing to their unique structural and chemical properties. ${ }^{1} \mathrm{~N}$ Sulfonyl amidines are a special class of amidines, which serve as essential intermediates in numerous important organic reactions, ${ }^{2}$ and can be useful building blocks for synthesizing heterocyclic compounds ${ }^{3}$ or chelating ligands for transition metals. ${ }^{4}$ In addition, sulfonyl amidines have wide applications in biopharmaceutical molecular design and the exploration of lead compounds in drug discovery. ${ }^{5}$ Over the past decade, research regarding the formation of $N$-sulfonyl amidines has led to remarkable progress. ${ }^{6}$

Recently, multicomponent reaction (MCR) methods have attracted considerable attention for their potential ability to access biologically active compounds ${ }^{7}$ and molecules relevant to drug discovery. ${ }^{8} N$-Sulfonylamidines fit these criteria because they are found in numerous biologically active natural products and important biopharmaceuticals. ${ }^{5}$ Various elegant MCR methods involving the formation of $N$-sulfonylamidines have already been developed. For example, a Cu-catalyzed three-component tandem reaction between (i) sulfonyl azides $/$ amides, ${ }^{10}$ (ii) alkynes, and (iii) primary, secondary, or tertiary amines or ammonium salts has been described (Scheme 1a). Another recently reported Cu-catalyzed three-component approach employed sulfonyl chlorides, sodium azides, and amines (Scheme 1b). ${ }^{11}$ Additionally, Bi and co-workers ${ }^{12}$ described a silver-catalyzed, one-pot, four-component reaction involving terminal alkynes reacting directly with trimethylsilyl azide $\left(\mathrm{TMSN}_{3}\right.$ ), sodium sulfinate, and sulfonyl azide (Scheme 1c). Phukan et $a .^{13}$ described a metal-free strategy for the synthesis of disubstituted sulfonyl amidines via a one-pot reaction between tert-

${ }^{a}$ School of Chemistry and Chemical Engineering, Xinjiang Normal University, Urumqi, Xinjiang, 830054, P. R China. E-mail: arahman@xjnu.edu.cn

${ }^{b}$ Xinjiang Key Laboratory of Energy Storage and Photoelectrocatalytic Materials, Urumqi 830054, China

$\dagger$ Electronic supplementary information (ESI) available. CCDC 2055586 and 2055587. For ESI and crystallographic data in CIF or other electronic format see DOI: $10.1039 / \mathrm{d} 1 \mathrm{ra} 00772 \mathrm{f}$ butylisonitrile and $N, N$-dibromoaryl sulfonamides in the presence of a nitrile compound in aqueous media (Scheme 1d), and other groups have applied similar methods. ${ }^{14}$ However, most protocols still typically require special reagents, including transition metal catalysts or expensive and potentially explosive sulfonyl azides, and they often proceed at elevated temperatures. Therefore, the development of an efficient and practical method for the synthesis of $N$ sulfonylamidine derivatives is critical. Although tri-substituted sulfonyl(form)amidines have been widely explored, ${ }^{6 a-r}$ the synthesis of di-substituted $N$-sulfonyl formamidines is rare in the literature; to our knowledge, only one research paper (from Jacobson and coworkers, 1977) ${ }^{15}$ has described the synthesis of $N, N^{\prime}$-di-substituted sulfonyl formamidines using sulfonamide and isocyanides in the presence of a copper catalyst.

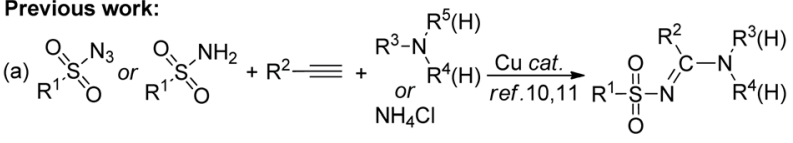

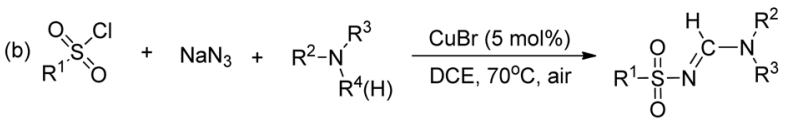

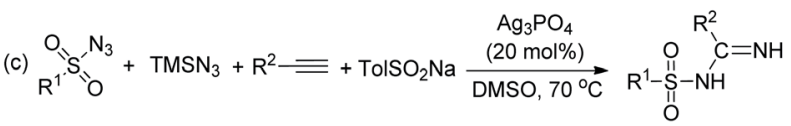

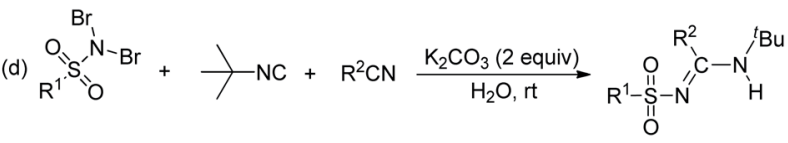

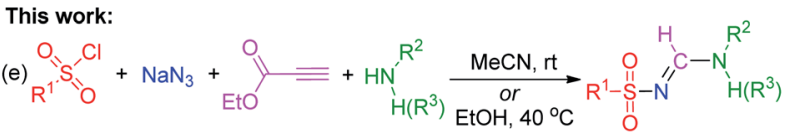

Scheme 1 Multicomponent reactions for the synthesis of $N$ sulfonylamidines. 
In recent years, the reaction of enamines and azides has received increasing interest due to their diversified chemical reactions. ${ }^{16}$ More recently, Wan and co-workers developed methods for the direct synthesis of tri-substituted, ${ }^{6 o}$ and $\mathrm{NH}_{2}$ featured $^{6 t}$ sulfonyl (form)amidines by using $N, N$-disubstituted enaminoesters and $\mathrm{NH}_{2}$-functionalized enaminone with sulfonylazide. However, NH-functionalized enaminone did not undergo this reaction. In addition these reactions require 5.0 and 2.5 equiv. of sulfonyl azides, respectively, and the desired tri-substituted $\mathrm{N}$-sulfonyl formamidine was obtained in a lower yield. We hypothesized that sulfonyl chlorides, $\mathrm{NaN}_{3}$, primary (secondary) amine, and ethyl propiolate might react under same conditions to generate $N$-sulfonyl formamidines via in situ formation of corresponding NH-mono and $\mathrm{N}, \mathrm{N}$-disubstituted enaminoesters ${ }^{\mathbf{1 7}}$ and sulfonyl azides. ${ }^{\mathbf{1 8}}$ On the basis of our previous work regarding the synthesis of $N$-sulfonyl formamidine, ${ }^{19}$ we herein describe a mild and simple one-pot multicomponent method for the synthesis of di- and trisubstituted $N$-sulfonyl formamidines (Scheme 1e). This catalyst-free cascade approach avoids any metals and additives, all of the substrates are commercially available, inexpensive and easily handled. In addition these reactions can be carried out in an open atmosphere at room temperature.

To evaluate the feasibility of this hypothesis, we initially considered the formation of di-substituted sulfonyl formamidines, and tosyl chloride ( $\mathrm{TsCl} ; \mathbf{1 a}), \mathrm{NaN}_{3}$ (2), ethyl propiolate (3), and butylamine (4a) were chosen as model substrates to optimize the reaction conditions (Table 1). The

Table 1 Optimization of reaction conditions ${ }^{a}$

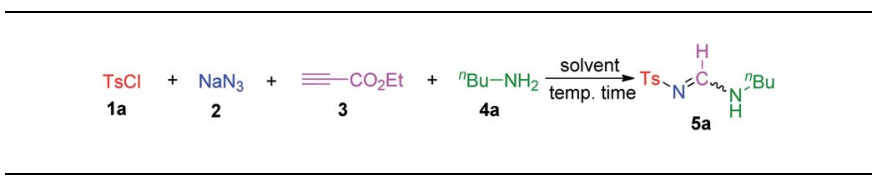

\begin{tabular}{lllll}
\hline Entry & Solvent & Temp. & $t(\mathrm{~h})$ & Yield $^{b}(\%)$ \\
\hline 1 & EtOH & $\mathrm{rt}$ & 6 & 38 \\
2 & DCM & $\mathrm{rt}$ & 12 & 36 \\
3 & MeCN & $\mathrm{rt}$ & 8 & 56 \\
4 & Toluene & $\mathrm{rt}$ & 18 & 12 \\
5 & EtOAc & $\mathrm{rt}$ & 18 & 10 \\
6 & DMF & $\mathrm{rt}$ & 18 & Trace \\
7 & THF & $\mathrm{rt}$ & 8 & 11 \\
8 & $\mathrm{H}$ O & $\mathrm{rt}$ & 8 & 7 \\
9 & MeOH & $\mathrm{rt}$ & 8 & 18 \\
$\mathbf{1 0}$ & MeCN & rt & $\mathbf{8}$ & $\mathbf{6 7}$ \\
$11^{e}$ & MeCN & $\mathrm{rt}$ & 8 & 66 \\
12 & MeCN & $40{ }^{\circ} \mathrm{C}$ & 5 & 60 \\
13 & MeCN & $0{ }^{\circ} \mathrm{C}$ & 12 & 30 \\
$14^{f}$ & MeCN & $\mathrm{rt}$ & 5 & 30 \\
$15^{g}$ & MeCN & $\mathrm{rt}$ & 6 & 65 \\
$16^{h}$ & MeCN & $\mathrm{rt}$ & 6 & 68
\end{tabular}

${ }^{a}$ Reactions were performed with $\mathbf{1 a}(1.2 \mathrm{mmol}), 2$ (1.2 mmol), 3 (1.0 $\mathrm{mmol})$, and $4 \mathrm{a}(1.0 \mathrm{mmol})$ in $4 \mathrm{~mL}$ of solvent at room temperature under open-air conditions, unless otherwise noted. ${ }^{b}$ Isolated yield after column chromatography. ${ }^{c} 1 \mathrm{1a}$ and 2 were $1.5 \mathrm{mmol} .{ }^{d} \mathrm{~N}$ Butyltosyl amide was isolated in $24 \%$ yield. ${ }^{e}$ 1a and 2 were $1.8 \mathrm{mmol}$. ${ }^{f}$ 3-Butyn-2-one was used instead of ethyl propiolate (3). ${ }^{g}$ Under $\mathrm{O}_{2}(1$ atm) atmosphere. ${ }^{h}$ Under $\mathrm{N}_{2}$ atmosphere. reaction proceeded smoothly in ethanol (EtOH) at room temperature and afforded di-substituted sulfonylformamidine 5a, in 38\% yield (with nearly a $7: 3$ syn/anti isomeric ratio) together with $N$-butyltosyl amide as by-product (entry 1). Following investigations with other solvents (entries 1-9), it was determined that acetonitrile (MeCN) led to the best yield (entry 3) among the tested solvents (i.e., toluene, EtOAc, DMF, THF, $\mathrm{H}_{2} \mathrm{O}$, and $\mathrm{MeOH}$ ). Closer inspection of the reaction (monitored using thin-layer chromatography; TLC) revealed that the intermediate $\mathrm{TsN}_{3}$ (generated from $1 \mathrm{a}$ and 2), was consumed easily. Probably the excess of sulfonyl azide play a crucial role on the reaction yield. ${ }^{12}$ Therefore we thought to increase the substrate loading of $\mathbf{1 a}$ and 2 under the same reaction conditions, when both the 1a and 2 dosages were increased to 1.5 equiv. the highest yield $(67 \%)$ of desired 5 a and $24 \%$ of $N$-butyltosyl amide (byproduct) were obtained, respectively (entry 10). With addition of more 1a and 2, the yield did not improve further (entry 11). When the reaction temperature was increased to $40{ }^{\circ} \mathrm{C}$ or decreased to $0{ }^{\circ} \mathrm{C}$, the yield was reduced to $60 \%$ or $30 \%$, respectively (entries 12 and 13). When, 3-butyn-2-one was used in place of ethyl propiolate (3), and the same product was isolated in 30\% yield (entry 14). Whereas, under $\mathrm{O}_{2}$ or $\mathrm{N}_{2}$ atmosphere, the yields were no longer improved, and afforded $65 \%$ and $68 \%$ yields of desired product, respectively (entries 15 and 16). Therefore, the optimal reaction conditions (entry 11) were set as follows: TsCl (1.5 equiv.), $\mathrm{NaN}_{3}$ (1.5 equiv.), ethyl propiolate (1.0 equiv.), and $\mathrm{BuNH}_{2}$ (1.0 equiv.) in $\mathrm{MeCN}$ at room temperature.

Applying the optimized reaction conditions, we explored the substrate scope of this reaction (Table 2). The aromatic sulfonyl chlorides were first investigated using $n$-butylamine, and it was observed that electron-donating or electron-withdrawing groups on the benzene ring (5a-5e) were tolerated well by this reaction, generating the desired products in moderate to good yields with 7:3 E-syn/anti isomeric ratios. With electron-

Table 2 Synthesis of di-substituted sulfonyl formamidines ${ }^{a, b, c}$

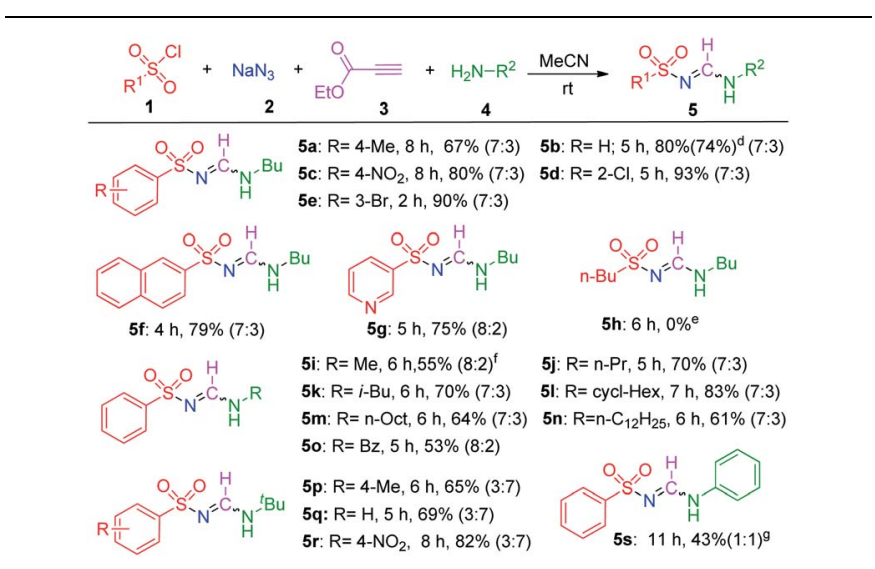

${ }^{a}$ Reactions were performed with 1 (1.5 mmol), 2 (1.5 mmol), 3 (1 mmol), and 4 $(1 \mathrm{mmol})$ in $2.0 \mathrm{~mL}$ of solvent at room temperature under open-air conditions, unless otherwise noted. ${ }^{b}$ Isolated yield after column chromatography. ${ }^{c}$ The ratio of the E-syn and E-anti isomers is given in parentheses. ${ }^{d}$ Gram scale reaction after 7 h. ${ }^{e}$ 4-Ethoxycarbonyl-1H-1,2,3-triazole was isolated in $70 \%$ yield. ${ }^{f}$ Methylamine aqueous solution was used. ${ }^{g}$ Reaction was performed in an $\mathrm{MeCN} / \mathrm{H}_{2} \mathrm{O}(3: 1)$ solvent mixture at $80{ }^{\circ} \mathrm{C}$. 
withdrawing groups, such as $\mathrm{NO}_{2}, \mathrm{Cl}$, and $\mathrm{Br}$, the yields were relatively higher than those obtained with substrates containing electron-donating groups. The best yield was obtained (5d) when using 2-chlorobenzenesulfonyl chloride, which revealed that the substituent on the benzene ring had a significant effect on the reaction yield. Then, naphthalene sulfonyl chloride and 3-pyridinyl chloride were employed under the standard conditions, and $79 \%$ and $75 \%$ yields were isolated, respectively (5f and 5g). Unfortunately, this methodology did not work with aliphatic sulfonyl chloride; when $n$-butyl sulfonyl chloride was used as a reaction partner, the desired product (5h) was not detected. Interestingly, the 4-ethoxycarbonyl-1H-1,2,3-triazole was isolated with $70 \%$ yield. In addition, benzyl sulfonyl chloride was tested, and the same product was observed in $24 \%$ yield under identical reaction conditions. A similar product was synthesised from enaminone and tosyl azide. ${ }^{\mathbf{6} d}$

Next, the scope of linear, branched, and cyclic primary aliphatic amines was studied, and it was determined that the amine structure did not appreciably influence the reaction yield because moderate to good yields were obtained with similar isomeric ratios (5i-5o). When tert-butylamines were used as substrates, satisfactory yields of the desired products were observed (5p-5r). Interestingly, the syn/anti rotameric ratios of the products changed to $3: 7$, and this observation was likely attributed to the effect of the bulky tert-butyl group on the molecular configuration.

It is worth mentioning that only a trace amount of 5s was observed when aniline was treated under standard conditions. However, the same reaction yield (43\%) of the desired products (with a $1: 1$ syn/anti rotameric ratio) was obtained in a MeCN/ $\mathrm{H}_{2} \mathrm{O}$ solvent mixture at elevated temperature with a longer reaction time. This special condition is likely required because of the poor reactivity between aniline and ethyl propiolate. ${ }^{20}$

To further clarify the structural properties of these sulfonyl formamidines, the nuclear magnetic resonance (NMR) spectra and X-ray single crystal structural data were examined. All of the products had two sets of signals in both their ${ }^{1} \mathrm{H}$ - and ${ }^{13} \mathrm{C}-\mathrm{NMR}$ spectra (see the ESI $\dagger$ ). In the ${ }^{1} \mathrm{H}$-NMR spectra, we observed that the imide $(\mathrm{CH}=\mathrm{N})$ proton appeared as two doublets, with different intensities and coupling constants $(J \approx 13 \mathrm{~Hz}$ and 6.0 $\mathrm{Hz}$ ). The signals corresponding to the $\mathrm{N}-\mathrm{H}$ proton also appeared as two doublets or broad peaks with different intensities. These results confirmed the formation of di-substituted sulfonyl formamidines as either the Z-syn/anti or E-syn/antiisomeric/rotameric forms (Fig. 1a). ${ }^{15}$

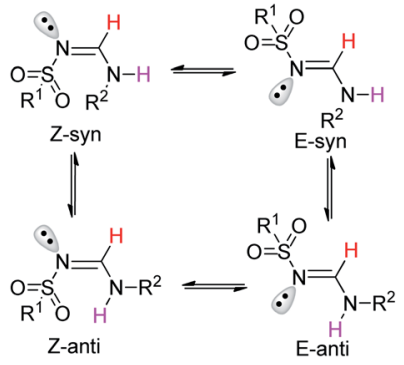

(a)

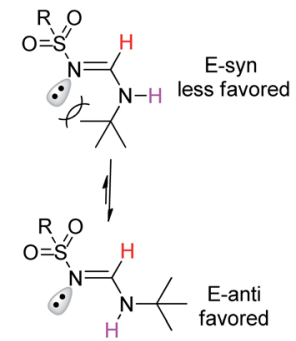

(b)
Fig. 1 (a) Geometrical/rotational isomers of $N$-alkyl- $N^{\prime}$-sulfonyl formamidine. (b) The effect of the tert-butyl group on the configuration.

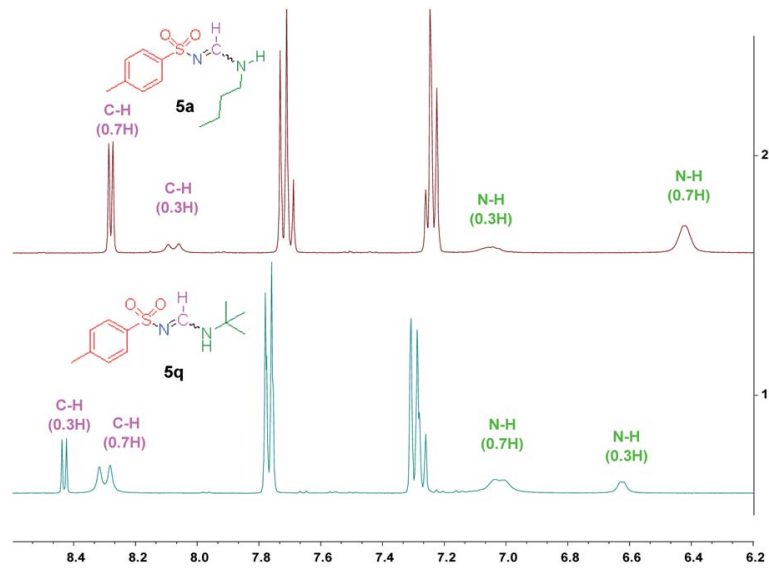

Fig. $2{ }^{1} \mathrm{H}$ NMR spectrum of compounds $5 \mathrm{a}$ and $5 \mathrm{q}$.

Additionally, on the basis of the ${ }^{1} \mathrm{H}-\mathrm{NMR}$ spectra, we observed that the syn/anti rotameric ratios were nearly $7: 3$ for linear and less branched $N$-alkyl- $N^{\prime}$-sulfonyl formamidines; in contrast, the $N$-tert-butyl- $N$-sulfonyl formamidines had syn/anti ratios of $3: 7$ (see the ESI $\dagger$ and Fig. 2). This result was attributed to the fact that in the syn configuration, the bulky tert-butyl group introduces more steric hindrance, causing this form to be relatively less favored (Fig. 1b).

The NMR results are consistent with the X-ray single crystal data. $^{21}$ For example, 5c was mainly produced in the E-syn configuration (Fig. 3), but $\mathbf{5 r}$ was predominantly generated in the E-anti form (Fig. 4). Therefore, we concluded that the linear and less branched $N$-alkyl- $N^{\prime}$-sulfonyl formamidines exist mainly as $E$-syn isomers, and the $N$-tert-butyl- $N^{\prime}$-sulfonyl formamidines exist predominantly in the $E$-anti isomeric form.

To elucidate the reaction mechanism, a series of control experiments were carried out (Scheme 2). First, the tosyl

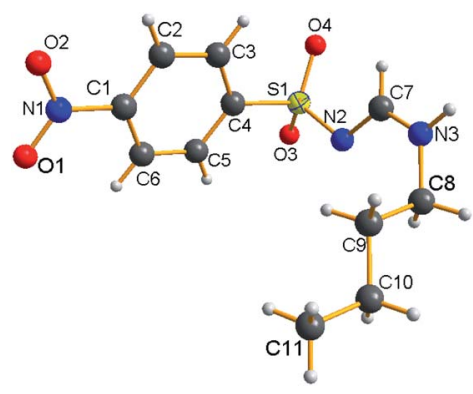

Fig. 3 X-ray single crystal structure of 5c (E-syn), CCDC: $2055587 . \dagger$

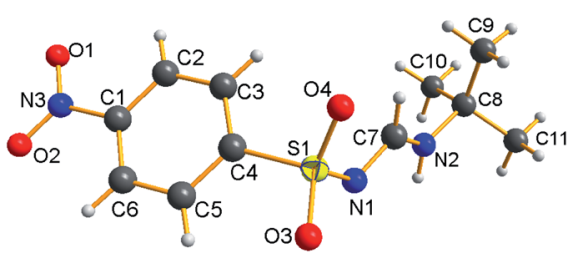

Fig. 4 X-ray single crystal structure of 5r (E-anti), CCDC: $2055586 . \dagger$ 
(a) $\underset{\mathbf{1 a}}{\mathrm{TsCl}}+\underset{\mathbf{2}}{\mathrm{NaN}_{3}} \stackrel{\text { standard conditions }}{\stackrel{90 \% \text { yield }}{\longrightarrow}} \underset{\mathbf{A}}{\mathrm{Ts}-\mathrm{N}=\mathrm{N}=\mathrm{N}}$

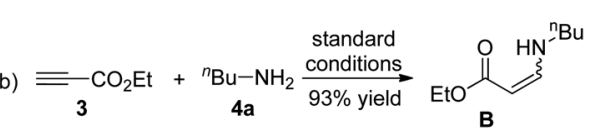

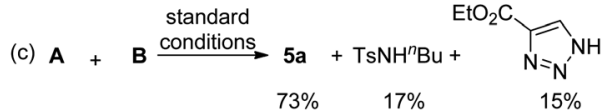

Scheme 2 Control experiments

chloride (1a) and $\mathrm{NaN}_{3}$ (2) were conducted under standard conditions and isolated $90 \%$ yield of tosylazide (A) (Scheme $2 \mathrm{a}$ ). After that the reaction of ethyl propiolate (3) and butylamine (4a) gave 93\% yield of enaminoester (B) under same conditions (Scheme 2b). This indicates that established reaction conditions are suitable for the formation of two intermediates. Next the tosylazide (A) was treated with enaminoester (B) and isolated $73 \%$ of desired 5a together with $17 \%$ of $N$-butyltosyl amide and $15 \%$ of 4 -ethoxycarbonyl-1H-1,2,3-triazole, respectively (see the ESI, S6 $\dagger$ ). This result revealed that the 1,2,3-triazole and $\mathrm{N}$ substituted sulfonamide were eliminated after formation of two intermediates.

On the basis of the experimental results obtained in the present study and a literature survey, ${ }^{16}$ a potential mechanism for the MCR was proposed (Scheme 3). First, the ethylpropiolate and amine reacted to generate enaminoester (B), ${ }^{17}$ while sulfonylazide (A) ${ }^{\mathbf{1 8}}$ was simultaneously formed from sulfonyl chloride and $\mathrm{NaN}_{3}$ under the same conditions. Then, the triazoline intermediate $(\mathbf{C})$ was produced from active components $\mathbf{A}$ and $\mathbf{B}$ through a 1,3-dipolar cycloaddition reaction. ${ }^{22}$ The subsequent cycloreversion of the intermediate $\mathbf{C}$ and release of one molecule of ethyldiazoacetate afforded the desired product 5 (route, a). ${ }^{23}$ The elimination of corresponding sulfonamide from $\mathbf{C}$ yields 4-ethoxycarbonyl- $1 H$-1,2,3-triazole (route, b). ${ }^{24}$

After a thorough examination of the synthesis of disubstituted $N$-sulfonyl formamidines, the developed MCR was further extended to the synthesis of tri-substituted sulfonyl formamidines by using secondary amines. First, the reaction between $\mathrm{TsCl}$ (1a), $\mathrm{NaN}_{3}$ (2), ethyl propiolate (3), and diethylamine (6a) was optimized (for details, see ESI, $\dagger$ p. S3), and the desired tri-substituted sulfonyl formamidine (7a) was isolated in $91 \%$ yield under the optimized conditions. The substrate scopes of the reactions were explored, and the results are

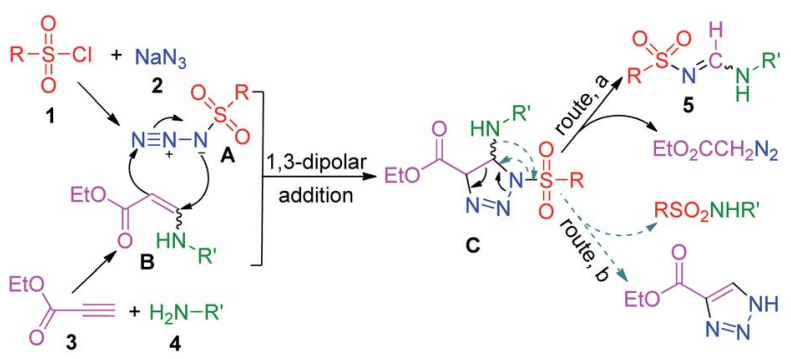

Scheme 3 Proposed reaction mechanism.
Table 3 Synthesis of tri-substituted sulfonyl formamidines ${ }^{a, b}$

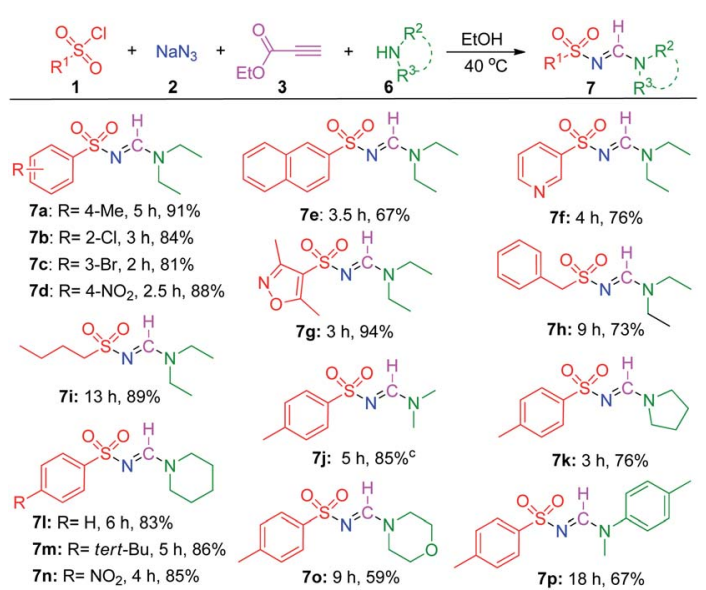

${ }^{a}$ Reactions were performed with 1 (1.5 mmol), 2 (1.5 mmol), 3 (1 mmol), and $6(1 \mathrm{mmol})$ in $4 \mathrm{~mL}$ of solvent at room temperature under open-air conditions, unless otherwise noted. ${ }^{b}$ Isolated yield after column chromatography. ${ }^{c}$ Dimethylamine aqueous solution was used.

presented in Table 3 . First, we investigated the reactivity of various sulfonyl chlorides under the optimized conditions. Arylsulfonyl chlorides bearing electron-donating or electronwithdrawing groups on their benzene rings were well tolerated by this reaction process, and generated the desired products in good yields (7a-7d). Moreover, with naphthalene sulfonyl chloride, the reaction proceeded smoothly, and the desired product 7e was obtained in a satisfactory yield. Hetero aromatic sulfonyl chlorides were also tolerated by this reaction, and the best yield (7g) was obtained using 3,5dimethylisoxazole-4-sulfonyl chloride. Notably, the aliphatic sulfonyl chlorides, i.e., benzylsulfonyl chloride and butylsulfonyl chloride, afforded the products $7 \mathbf{h}$ and $7 \mathbf{i}$ in $73 \%$ and $89 \%$ isolated yields, respectively. Interestingly, when aliphatic sulfonyl chlorides and secondary amine were tested, the 4ethoxycarbonyl-1H-1,2,3-triazole was not observed. This indicates that the $\mathrm{N}, \mathrm{N}$-disubstituted triazoline intermediate (see the Scheme 3) preferentially undergoes cycloreversion and eliminate ethyldiazoacetate to form sulfonyl amidine.

Next, dimethylamine was tested, and the desired product, $\mathbf{7 j}$, was isolated in good yield (85\%). When the cyclic and heterocyclic secondary amines, such as pyrrolidine, piperidine, and morpholine were used as the starting materials, the corresponding sulfonylamidines (7k-7o) were obtained with yields between $59 \%$ and $86 \%$. Finally, $N$-methylaniline reacted slowly and led to a $67 \%$ isolated yield (7p).

On the basis of the ${ }^{1} \mathrm{H}$ and ${ }^{13} \mathrm{C}$-NMR spectra of the trisubstituted $\mathrm{N}$-sulfonyl formamidines (one set of signals in both types of spectra, see the ESI $\dagger$ ), it was determined that these reactions produced only the $E$-isomer; this result is consistent with earlier reports. ${ }^{25}$

Finally, aqueous ammonia was used as a reaction partner, but unfortunately, the expected mono-substituted $\mathrm{N}$-sulfonyl formamidine was not detected. 


\section{Conclusions}

In summary, a straightforward, one-pot, multicomponent method was developed for the synthesis of $\mathrm{di}^{-}$and trisubstituted $\mathrm{N}$-sulfonyl formamidines using readily accessible substrates under very mild conditions free of catalysts or other additives. This protocol is inexpensive to carry out and stepeconomic, so it provides a potential route for the construction of diverse $\mathrm{N}$-sulfonyl formamidines in moderate to high yields.

\section{Conflicts of interest}

There are no conflicts to declare.

\section{Acknowledgements}

This work was supported by the National Natural Science Foundation of China (No. 21762044), and Innovation Training Project of Xinjiang Undergraduate Education (No: S202010762017).

\section{Notes and references}

1 S. Patai, The Chemistry of Amidines and Imidiares, Wiley, New York, 1975.

2 T. Kumamoto and I. Ishikawa, Superbases for Organic Synthesis: Guanidines, Amidines, Phosphazenes and Related Organoctalysts, John Wiley \& Sons Press, West Sussex, 2009, p. 295.

3 (a) G. Brasche and S. L. Buchwald, Angew. Chem., Int. Ed., 2008, 47, 1932; (b) Y.-F. Wang, X. Zhu and S. Chiba, J. Am. Chem. Soc., 2012, 134, 3679; (c) M. A. McGowan, C. Z. McAvoy and S. L. Buchwald, Org. Lett., 2012, 14, 3800.

4 (a) J. Barker and M. Kilner, Coord. Chem. Rev., 1994, 133, 219; (b) A. Wusiman, X. Tusun and C. D. Lu, Eur. J. Org. Chem., 2012, 16, 3088.

5 (a) M. Y. Lee, M. H. Kim, J. Kim, S. H. Kim, B. T. Kim, I. H. Jeong, S. Chang, S. H. Kim and S.-Y. Chang, Bioorg. Med. Chem. Lett., 2010, 20, 541; (b) A. Goubet, A. Chardon, P. Kumar, P. K. Sharma and R. N. Veedu, Bioorg. Med. Chem. Lett., 2013, 23, 761.

6 Selective literatures for the synthesis of sulfonyl amidines.

(a) X. L. Xu, Z. C. Ge, D. P. Cheng, L. Ma, C. S. Lu, Q. F. Zhang, N. Yao and X. N. Li, Org. Lett., 2010, 12, 897; (b) L. Zhang, J. H. Su, S. J. Wang, C. F. Wan, Z. G. Zha, J. F. Z. Du and Y. Wang, Chem. Commun., 2011, 47, 5488; (c) M. Aswad, J. Chiba, T. Tomohiro and Y. Hatanaka, Chem. Commun., 2013, 49, 10242; (d) S. Chen, Y. Xu and X. Wan, Org. Lett., 2011, 13, 6152; (e) N. Chandna, N. Chandak, P. Kumar, J. K. Kapoorb and P. K. Sharma, Green Chem., 2013, 15, 2294; (f) K. Hajibabaei and H. ZaliBoeini, Synlett, 2014, 25, 2044; (g) J. Chen, Y. P. Guo, M. H. Sun, G. T. Fan and L. Zhou, Chem. Commun., 2014, 50, 12367; $(h)$ L. Dianova, V. Berseneva, T. Beryozkina, I. Efimov, M. Kosterina, O. Eltsov, W. Dehaen and V. Bakulev, Eur. J. Org. Chem., 2015, 31, 6917; (i) J. Chen, W. Long, S. Fang, Y. Yang and X. Wan, Chem. Commun.,
2017, 53, 13256; (j) S. Y. Chow and L. R. Odell, J. Org. Chem., 2017, 82, 2515; ( $k$ ) J. Chen, W. Long, Y. Yang and X. Wan, Org. Lett., 2018, 20, 2663; (l) Y. Weiguang, H. Dayun, Z. Xiaobao, L. Dongping, W. Xinyan and H. Yuefei, Chem. Commun., 2018, 54, 8222; (m) J. Gui, H. Xie, H. Jiang and W. Zeng, Org. Lett., 2019, 21, 2804; (n) R. Ding, H. Chen, Y. Xu, H.-T. Tang, Y. Chen and Y. Pan, Adv. Synth. Catal., 2019, 361, 3656; (o) X. Zheng and J. P. Wan, Adv. Synth. Catal., 2019, 361, 5690; (p) F. Yi, Q. Sun, J. Sun, C. Fu and W. Yi, J. Org. Chem., 2019, 84, 6780; $(q)$ B. Kaboudin, S. Torabi, F. Kazemi and H. Aoyama, RSC Adv., 2020, 10, 26701; (r) W. Xia, B. Huang, C. Yang and J. zhou, Chem. Commun., 2020, 56, 5010; (s) Q. Gou, Z. Liu, T. Cao, X. Tan, W. Shi, M. Ran and J. Qin, J. Org. Chem., 2020, 85, 2092; $(t)$ G.-D. Wang, Y.-H. Guo and J.-P. Wan, Chin. J. Org. Chem., 2020, 40, 645; (u) X.-X. Zheng, Y.-Y. Liu and J.-P. Wan, Chin. J. Org. Chem., 2020, 40, 1891 and references cited therein.

7 (a) A. Dömling, Chem. Rev., 2006, 106, 17; (b) I. AkritopoulouZanze, Curr. Opin. Chem. Biol., 2008, 12, 324.

8 B. B. Touré and D. G. Hall, Chem. Rev., 2009, 109, 4439.

9 Selective literatures for the Synthesis of sulfonyl amidines by Cu-catalyzed MCRs. (a) I. Bae, H. Han and S. Chang, J. Am. Chem. Soc., 2005, 127, 2038; (b) S. Mandal, H. M. Gauniyal, K. Pramanik and B. Mukhopadhyay, J. Org. Chem., 2007, 72, 9753; (c) J. Kim, S. Y. Lee, J. Lee, Y. Do and S. Chang, J. Org. Chem., 2008, 73, 9454; (d) I. Yavari, S. Ahmadian, M. Ghazanfarpur-Darjani and Y. Solgi, Tetrahedron Lett., 2011, 52, 668; (e) J. Y. Kim, S. H. Kim and S. Chang, Tetrahedron Lett., 2008, 49, 1745; $(f)$ J. Wang, P. Lu and Y. Wang, Org. Chem. Front., 2015, 2, 1346; (g) T. D. Suja, K. V. L. Divya, L. V. Naik, A. R. Kumar and A. Kamal, Bioorg. Med. Chem. Lett., 2016, 26, 2072; (h) X. He, Y. Shang, J. Hu, K. Ju, W. Jiang and S. Wang, Sci. China Chem., 2012, 55, 214; (i) M. Xu, C. Kuang, Z. Wang and Q. Yang, Synlett, 2010, 17, 2664.

10 J. Kim, S. S. Stahl, J. Kim and S. S. Stahl, J. Org. Chem., 2015, 80, 2448.

11 W. Z. Bi, W. J. Zhang, Z. J. Li, X. Y. Xia, X. L. Chen, L. B. Qu and Y. F. Zhao, Eur. J. Org. Chem., 2019, 35, 6071.

12 B. Liu, Y. Ning, M. Virelli, G. Zanoni, E. A. Anderson and X. Bi, J. Am. Chem. Soc., 2019, 141, 1593.

13 D. Mishra, A. J. Borah, P. Phukan, D. Hazarika and P. Phukan, Chem. Commun., 2020, 56, 8408.

14 (a) S. Shojaei, Z. Ghasemi and A. Shahrisa, Tetrahedron Lett., 2017, 58, 3957; (b) M. Jagadale, P. Bhange, R. Salunkhe, D. Bhange, M. Rajmane and G. Rashinkar, Appl. Catal., A, 2006, 511, 95; (c) M. J. Kim, B. R. Kim, C. Y. Lee and J. Kim, Tetrahedron Lett., 2016, 57, 4070; (d) T. Yang, H. Cui, C. Zhang, L. Zhang and C. Y. Su, Inorg. Chem., 2013, 52, 9053; (e) Y. Huang, W. Yi, Q. Sun and F. Yi, $A d v$. Synth. Catal., 2018, 360, 3074; (f) J. Wang, J. Liu, H. Ding, J. Wang, P. Lu and Y. Wang, J. Org. Chem., 2015, 80, 5842; (g) J. Chen, W. Long, Y. Zhao, H. Li, Y. Zheng, P. Lian and X. Wan, Chinese J. Chem., 2018, 36, 857; $(h)$ B. Yao, C. Shen, Z. Liang and Y. Zhang, J. Org. Chem., 2014, 79, 936; (i) Y. Zhang and Z. Chen, Tetrahedron Lett., 2018, 59, 
4183; (j) Z. Zhang, B. Huang, G. Qiao, L. Zhu, F. Xiao, F. Chen and Z. Zhang, Angew. Chem., Int. Ed., 2017, 56, 4320.

15 P. Jakobsen and S. Treppendahl, Tetrahedron, 1977, 33, 3137. 16 (a) V. A. Bakulev, T. Beryozkina, J. Thomas and W. Dehaen, Eur. J. Org. Chem., 2018, 262 and references cited therein.; (b) J.-P. Wan, S. Cao and Y. Liu, Org. Lett., 2016, 18, 6034; (c) A. De Nino, P. Merino, V. Algieri, M. Nardi, M. L. Di Gioia, B. Russo, M. A. Tallarida and L. Maiuolo, Catalysts, 2018, 8, 364; (d) L. Yang, Y. Wu, Y. Yang, C. Wen and J.-P. Wan, Beilstein J. Org. Chem., 2018, 14, 2348; (e) L. Maiuolo, B. Russo, V. Algieri, M. Nardi, M. L. Di Gioia, M. A. Tallarida and A. D. Nino, Tetrahedron Lett., 2019, 60, 672.

17 M. Regitz, J. Hocker and A. Liedhegener, Org. Synth., 1973, 48, 36.

18 (a) X.-Y. Chen, L. Zhang, Y. Tang, S. Yuan, B. Zhu, G. Chen and X. Cheng, Synlett, 2020, 31, 878; (b) Y. I. Él'natanov and R. G. Kostyanovskii, Bull. Acad. Sci. USSR, Div. Chem. Sci. (Engl. Transl.), 1988, 37, 302; (c) N. A. Randive, V. Kumar and V. A. Nair, Mon. Chem., 2010, 141, 1329; (d) G. Choudhary and R. K. Peddinti, Green Chem., 2011, 13, 3290.
19 (a) A. Rouzi, R. Hudabaierdi and A. Wusiman, Tetrahedron, 2018, 74, 2475; (b) A. Wusiman and R. Hudabaierdi, Synth. Comm., 2017, 47, 2015.

20 D. R. Chisholm, R. Valentine, E. Pohl and A. Whiting, J. Org. Chem., 2016, 81, 7557.

21 CCDC 2055587 (5c) and 2055586 (5r) contain the supplementary crystallographic data for this paper. $\dagger$.

22 R. Fusco, G. Bianchetti, D. Pocar and R. Ugo, Chem. Ber., 1963, 96, 802.

23 (a) T. Gao, M. Zhao, X. Meng, C. Li and B. Chen, Synlett, 2011, 1281; (b) Y. Xu, Y. Wang and S. Zhu, J. Fluorine Chem., 2000, 104, 195; (c) A. Contini, E. Erba and S. Pellegrino, Synlett, 2012, 23, 1523.

24 (a) A. S. Maiorana, D. Pocar and P. Dalla Croce, Tetrahedron Lett., 1966, 7, 6043; (b) P. Zanirato, J. Chem. Soc., Perkin Trans. 1, 2002, 1420; (c) N. Kato, Y. Hamada and T. Shioiri, Chem. Pharm. Bull., 1984, 32, 2496; (d) N. Kawai, N. Kato, Y. Hamada and T. Shioiri, Chem. Pharm. Bull., 1983, 31, 3139. 25 S. Wang, Z. Wang and X. Zheng, Chem. Comm., 2009, 47, 7372 . 